\title{
A NOVEL IDEAL FLOATING INDUCTOR USING TRANSLINEAR CONVEYORS
}

\author{
IQBAL A. KHAN ${ }^{\mathrm{a} *}$ and MEHMOOD H. ZAIDI ${ }^{\mathrm{b} \dagger}$ \\ ${ }^{a}$ Department of Electronics Engineering, Aligarh Muslim University, Aligarh - 202002, India; \\ ${ }^{\mathrm{b}}$ Department of Electrical Engineering, Faculty of Engineering \& Technology, \\ Jamia Millia Islamia, Jamia Nagar, Okhla, New Delhi - 110025, India
}

(Received 18 August 2002; In final form 17 November 2002)

\begin{abstract}
An ideal floating inductor circuit using translinear conveyors is introduced. The floating inductor simulator uses two translinear conveyors and a single capacitor in its realization. The circuit provides the current controlled ideal floating inductance without any component matching constraints. Simulation results on the floating inductor simulator verify the theory.
\end{abstract}

Keywords: Active networks; Current conveyors; Active inductors

\section{INTRODUCTION}

Recently the translinear conveyors, i.e. current controlled conveyors (CCCIIs), have become popular because of their high performance coupled with the broad and linear electronic tunability they provide to circuit realizations. As a result, several filters, oscillators and impedance function simulators using CCCIIs have appeared in recent literature [1-6].

In this paper, a novel ideal floating inductor simulator (FIS) employing CCCIIs is presented. The circuit realizes an ideal simulator without any matching constraints. The realized circuit is studied in detail. The simulation results on the FIS exhibit a close conformity with the theory.

\section{CIRCUIT REALIZATION}

The ideal floating inductance simulator circuit is shown in Figure 1. The routine analysis yields the admittance matrix as:

$$
[Y]=\frac{1}{s L_{\mathrm{eq}}}\left[\begin{array}{ll}
+1 & -1 \\
-1 & +1
\end{array}\right], \quad \text { where } L_{\mathrm{eq}}=C R_{x 1} R_{x 2} .
$$

\footnotetext{
* Corresponding author. E-mail: iqbal.a.khan@mailcity.com

${ }^{\dagger}$ E-mail: zaidimh@rediffmail.com
} 


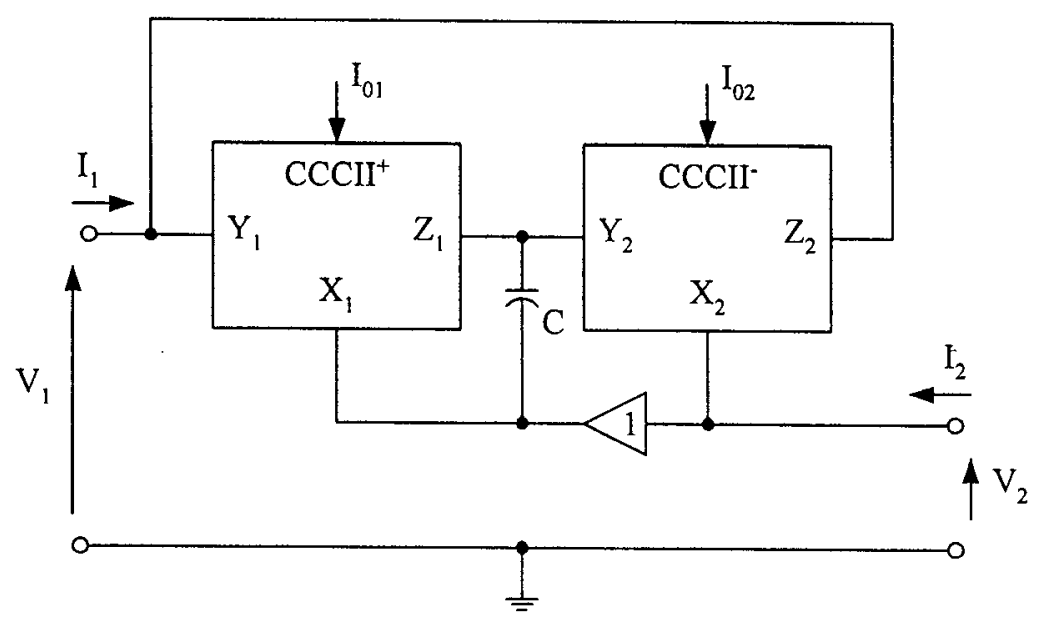

FIGURE 1 Proposed ideal floating inductance simulator (FIS).

Thus the circuit of Figure 1 realizes an ideal FIS with an inductance value $L_{\text {eq }}$ given by (1), where $R_{x 1}$ and $R_{x 2}$ are the parasitic resistances at $x$-input of the respective CCCIIs. The parasitic resistance $R_{x i}$ can be expressed as:

$$
R_{x i}=\frac{V_{T}}{2 I_{0 i}} \quad i=1,2
$$

where $V_{T}$ is the thermal voltage and $I_{0 i}(i=1,2)$ is the bias current of the $i$ th CCCIIs, which is tunable over several decades $[1,2]$. It is to be noted that the FIS of Figure 1 saves two CCCIIs and two external floating resistors at the cost of a voltage buffer as compared with the FIS of Ref. [7].

\section{SPICE SIMULATION AND VERIFICATIONS}

To validate the theory here, the FIS of Figure 1 has been used in the realization of a resonator of Figure 2. The floating inductor of Figure 2 is replaced by the FIS of Figure 1. The resonator was designed for a center frequency of $f_{0}=10 \mathrm{kHz}$, and $Q_{0}=1$ with

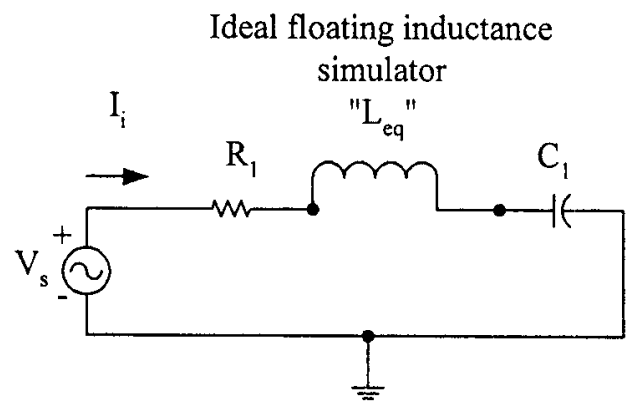

FIGURE 2 Prototype passive circuit for a resonator. 


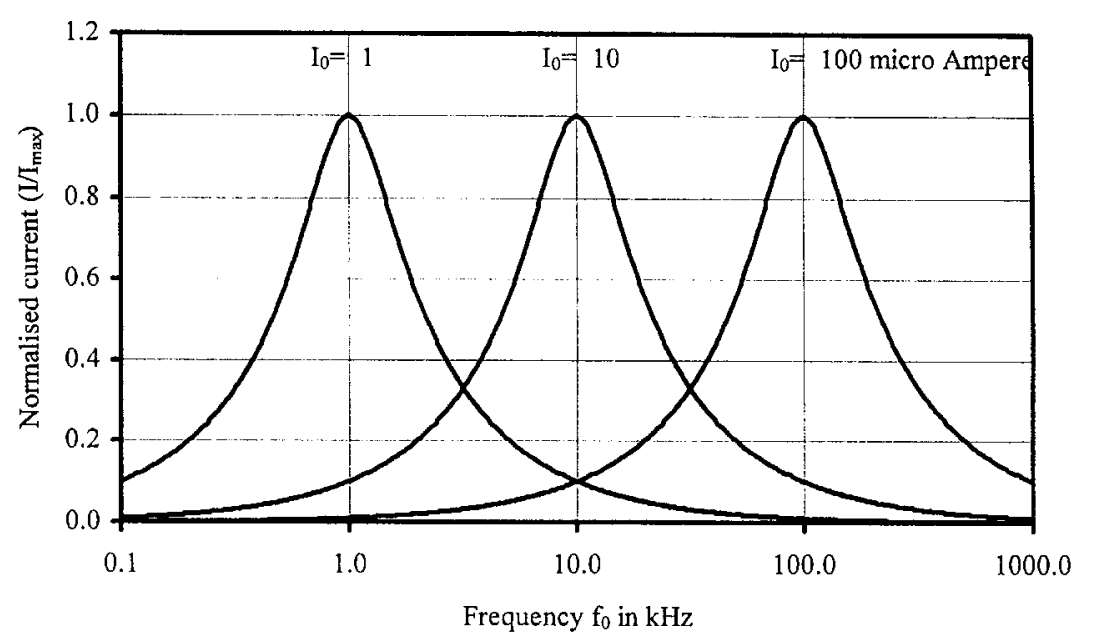

FIGURE 3 Simulated response of a FIS-based resonator for different $I_{0}$.

$I_{01}=I_{02}=I_{0}=10 \mu \mathrm{A}, C=C_{1}=12.242 \mathrm{nF}$ and $R_{1}=1.3 \mathrm{k} \Omega$. The designed circuit was simulated using PSPICE. The $\mathrm{CCCII}^{+}$and $\mathrm{CCCII}^{-}$were simulated using the realizations suggested in Ref. [4]. To demonstrate the electronic tunability, the center frequency of the resonator was tuned by controlling the value of the simulated inductance through the bias current $I_{0}$ for $1 \mu \mathrm{A}, 10 \mu \mathrm{A}$ and $100 \mu \mathrm{A}$. The frequency response curves of normalized currents $\left(I / I_{\max }\right)$ through the resonator are shown in Figure 3, which justifies the theory.

\section{CONCLUSIONS}

The current controlled conveyors have been used for the realization of an ideal floating inductance simulator. In the realization only two current controlled conveyors have been used along with the single capacitor and without any component matching constraints. The simulated FIS provides wide range electronic tunability. The simulation results of the simulated floating inductance show a close conformity with the theory.

\section{References}

[1] Fabre, A., Saaid, O., Wiest, F. and Boucheron, C. (1995). Current controlled band pass filter based on translinear conveyors. Electronics Letters, 31(20), 1727-1728.

[2] Kiranon, W., Kesron, J. and Wardkien, P. (1996). Current controlled oscillator based on translinear conveyors. Electronics Letters, 31(15), 1330-1331.

[3] Kiranon, W., Kesron, J. and Kamprasert, N. (1997). Electronically tunable multifunctional translinear-C filter and oscillator. Electronics Letters, 33(7), 573-574.

[4] Fabre, A., Saaid, O., Wiest, F. and Boucheron, C. (1997). Low power current mode second order band pass IF filter. IEEE Transactions on Circuits and Systems-II, 44(6), 436-444.

[5] Abuelma'atti, M. T. and Al-qahtani, M. A. (1997). A new current controlled multiphase sinusoidal oscillator using translinear conveyors. IEEE Transactions on Circuits and Systems-II, 34(8), 436-444; Abuelma'atti, M. T. and Al-qahtani, M. A. (1998). Low component current mode universal filter. Electronics Letters, 31(25), 881-885.

[6] Khan, I. A. and Zaidi, M. H. (2000). Multifunctional translinear-C current mode filter. Int. J. Electronics, 87(9), 1047-1051.

[7] Kiranon, W. and Pawarangkoon, P. (1997). Floating inductance based on current conveyors. Electronics Letters, 33(21), 1748-1748. 

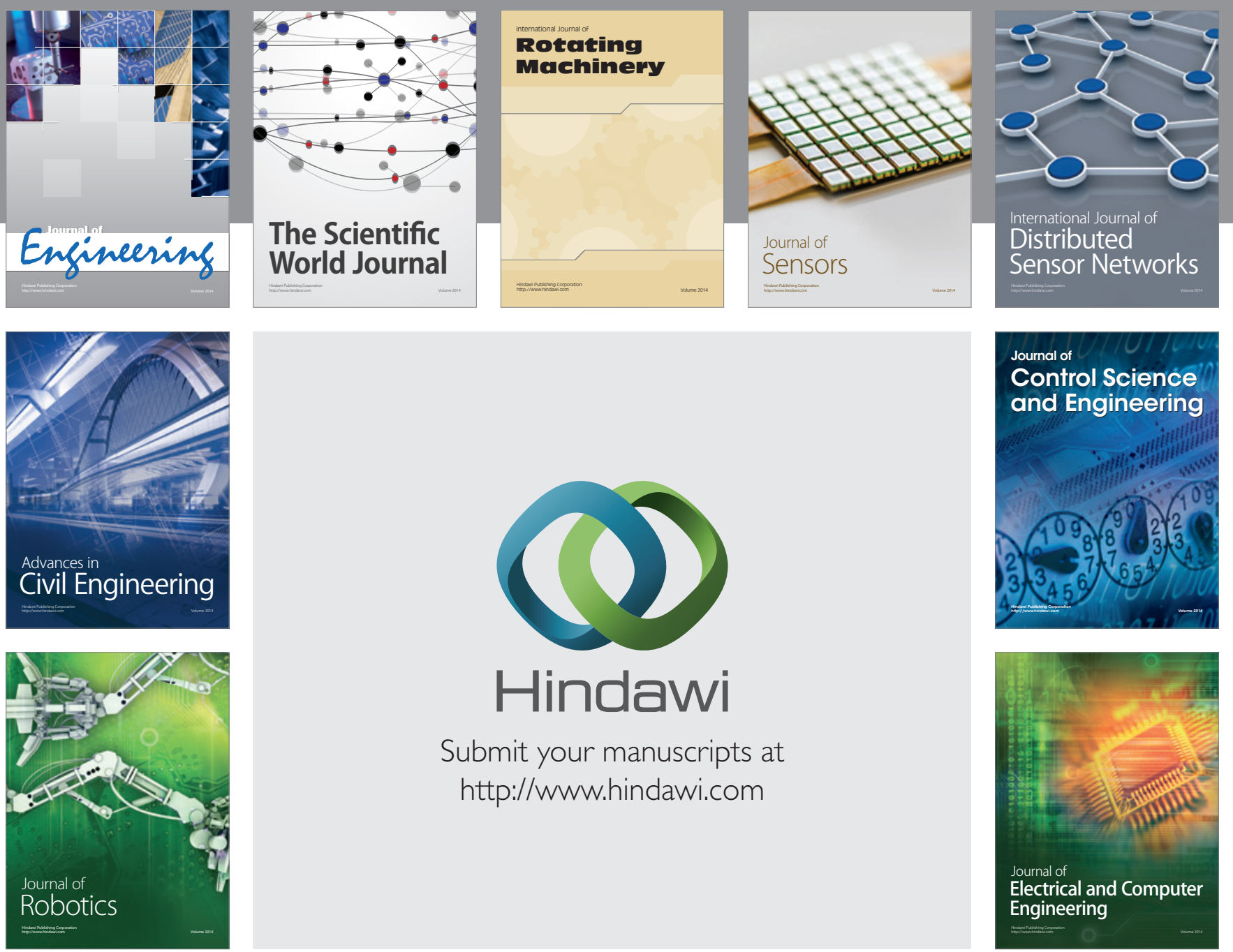

Submit your manuscripts at

http://www.hindawi.com
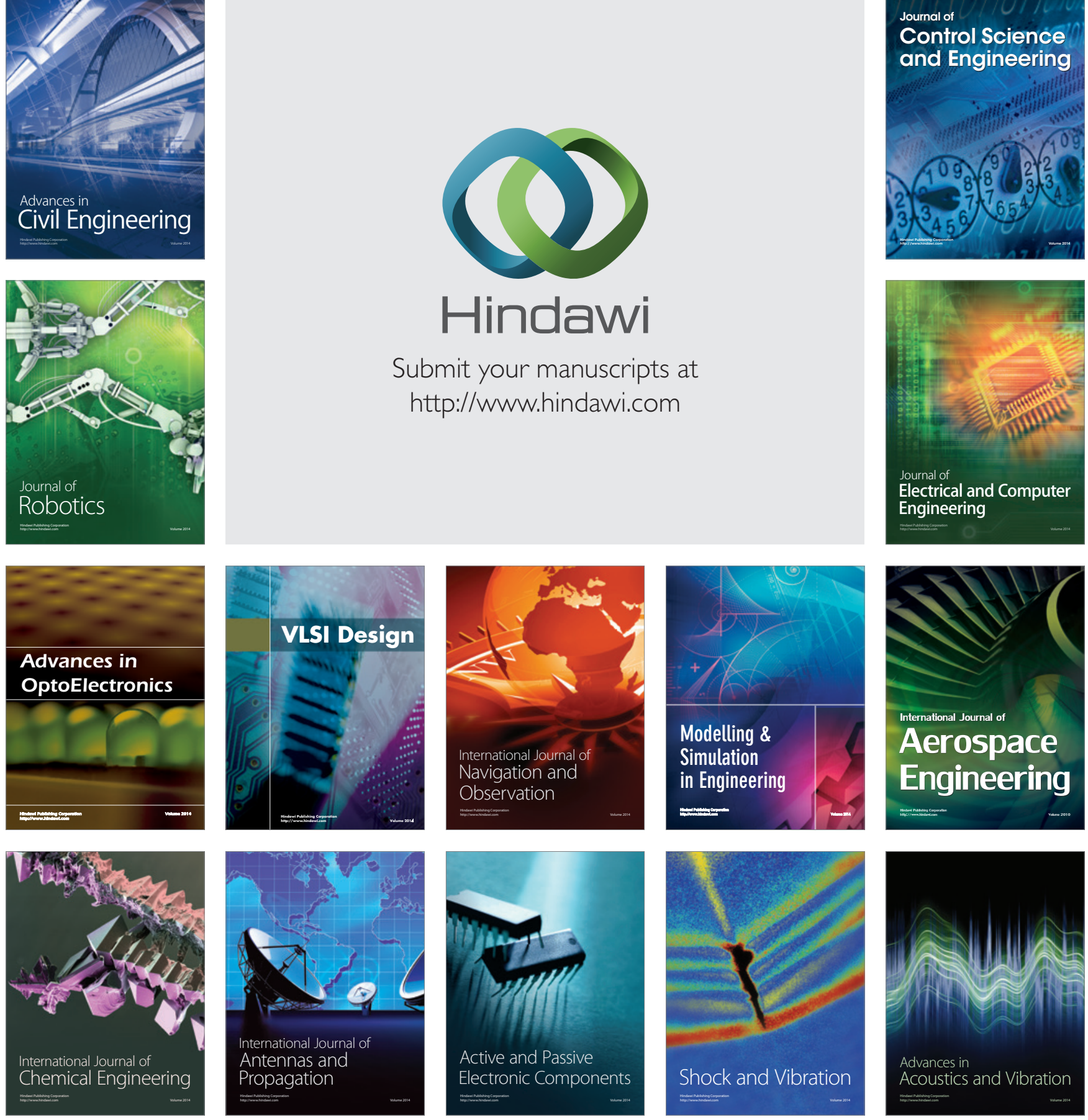